\begin{tabular}{|c|c|}
\hline Title & New Continuous Speech Feature A djustment for a Noise robust CSR System \\
\hline Author(s) & Sun, Yiming \\
\hline Citation & $\begin{array}{l}\text { グリーン回路とシステムに関する国際ワークショップ. 2011年11月4日 (金). 北海道大学情報科学研究科棟 } \\
\text { 11F17号室. 札幌市. (International Workshop on Green Circuits and Systems. Friday, 4 November, 2011. Room No.17, } \\
\text { 11th floor of Graduate School of Information Science and Technology, Hokkaido University. Sapporo City.) }\end{array}$ \\
\hline Issue Date & 2011-11-04 \\
\hline Doc URL & http:/hdl.handle.net/2115/47544 \\
\hline Type & conference presentation \\
\hline File Information & Yiming_SUN.pdf \\
\hline
\end{tabular}

Instructions for use 


\title{
New Continuous Speech Feature Adjustment for a Noise-robust CSR System
}

\author{
Yiming SUN \\ Information Communication Networks Laboratory \\ Graduate School of Information Science and Technology \\ Hokkaido University, Sapporo, Japan \\ sunny@icn.ist.hokudai.ac.jp
}




\section{Overview}

- Introduction

- Conventional Methods

- Robust Continuous Speech Recognition (CSR) System

- Noise Disturbance

- Block Based DRA

- Results 


\section{Introduction}

\section{$>$ Background}

- The dynamic range adjustment (DRA) method has been developed as the compensation method for such difference in an isolated word and phrase.

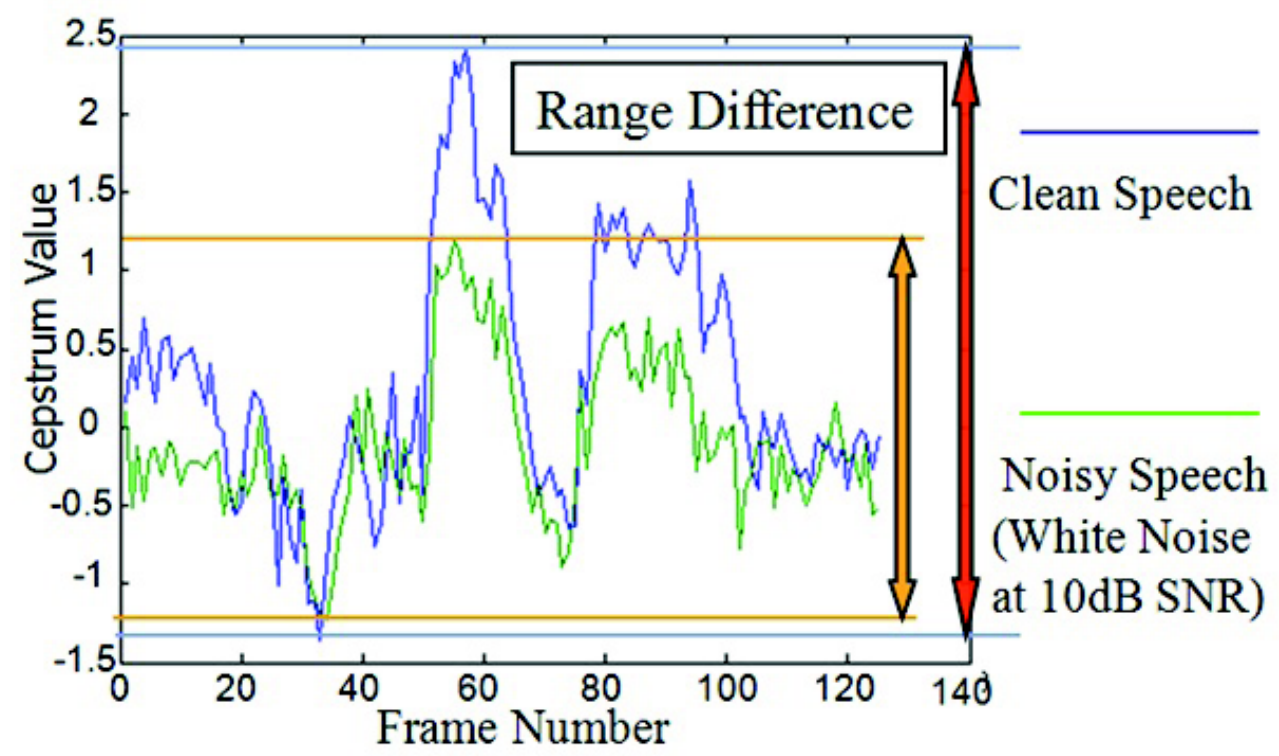

$>$ Summary

Fig.1 Noise influences in word feature vectors

- The proposed method introduces a short time length block chosen stochastically from the feature sequence of continuous speech.

- The modified technique of a DRA is proposed to a CSR system. 


\section{Conventional Methods}

> CMS: cepstrum means subtraction

- CMS is a channel normalization approach to compensate for the acoustic channel.

$>$ RSA: running spectrum analysis

- RSA is directly used in the modulation spectrum domain.

- RSA can realize an ideal processing filter.

- The components of low and high frequency are reduced by using RSA.

$>$ DRA: dynamic range adjustment

- Adjust the dynamic range of MFCC by normalizing the amplitude of each component. 


\section{Robust CSR System}

male : 153 persons

sentences: 23,651

Speech Feature Extraction

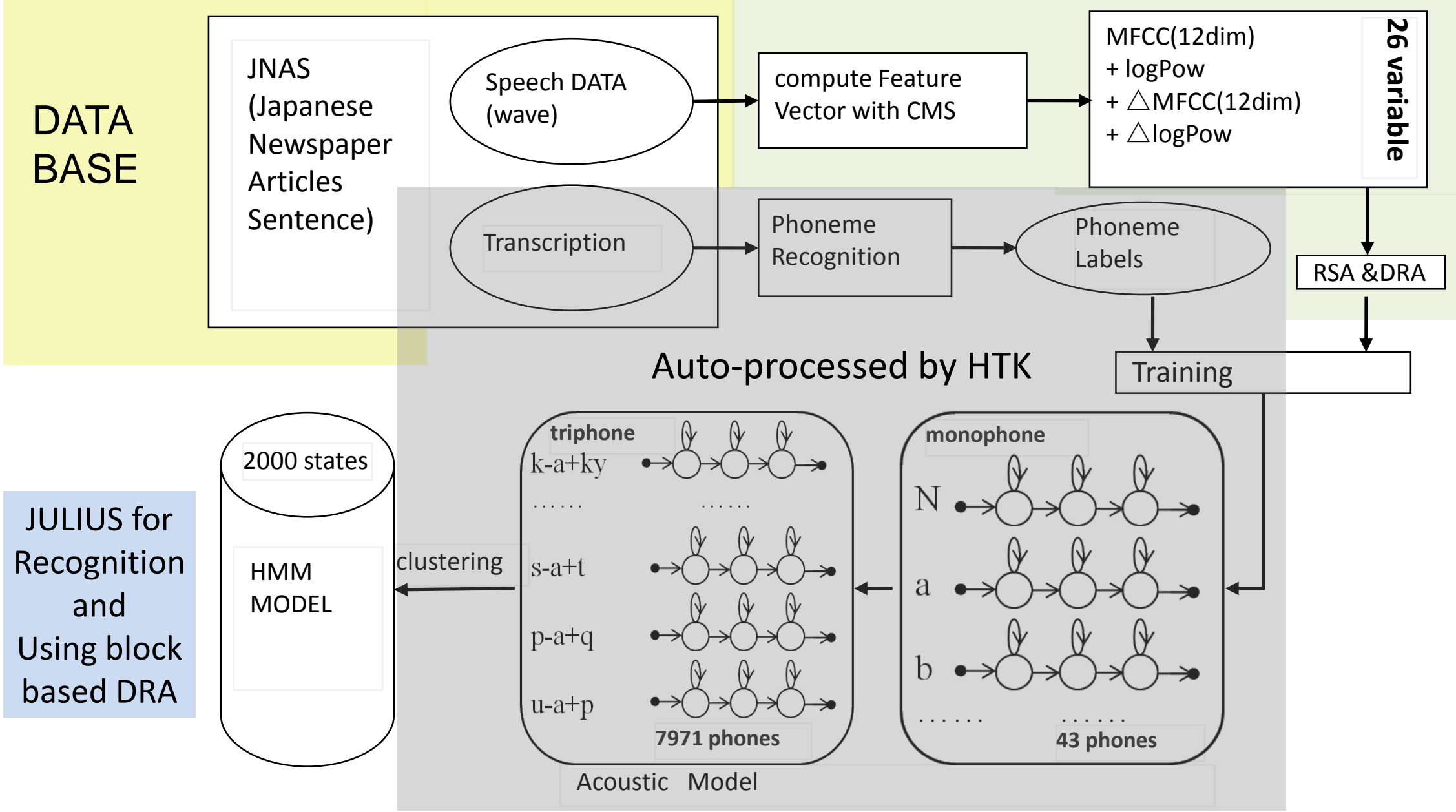

Fig.1 Structure of noise robust CSR system 


\section{Noise disturbance}

$>$ Sentence selection

- A continuous speech has many non-speech parts and only noises. These parts effect DRA inappropriately.

- The unbalance of several dynamic ranges existed in a continuous speech can be compensated. a. Continuous Speech

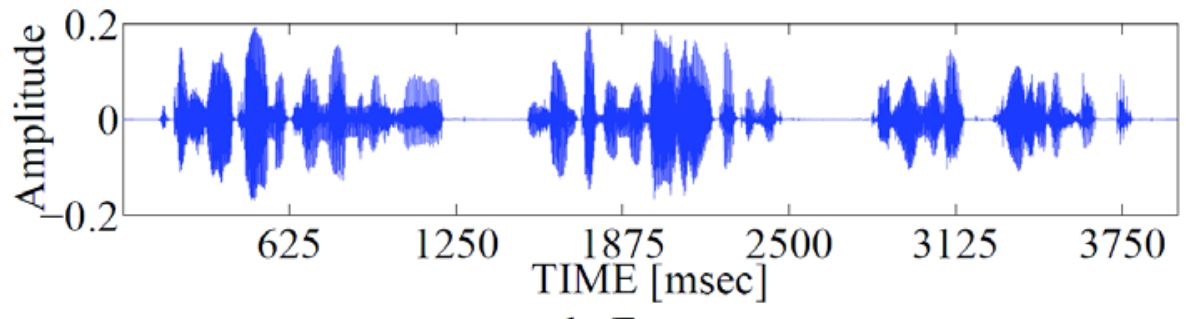

b. Energy

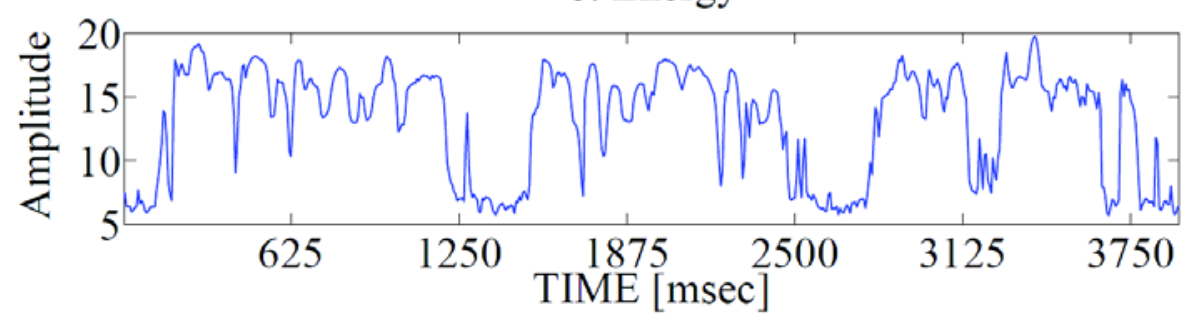

a. Continuous Speech
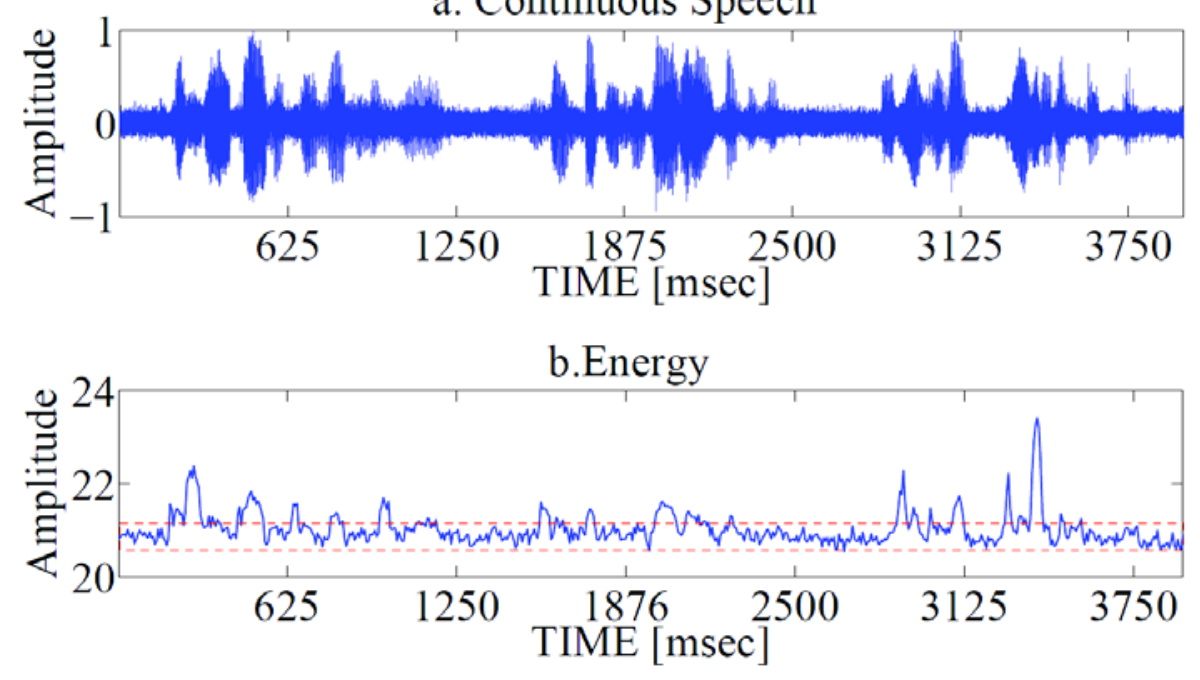

Fig.2 Noise disturbance in energy of continuous speech 


\section{Block Based DRA (1)}

\section{$>$ A short sentence and blocks}

- The algorithm finds out the maximum value in a given short sentence, i.e., "Peak Point" in Fig.3.

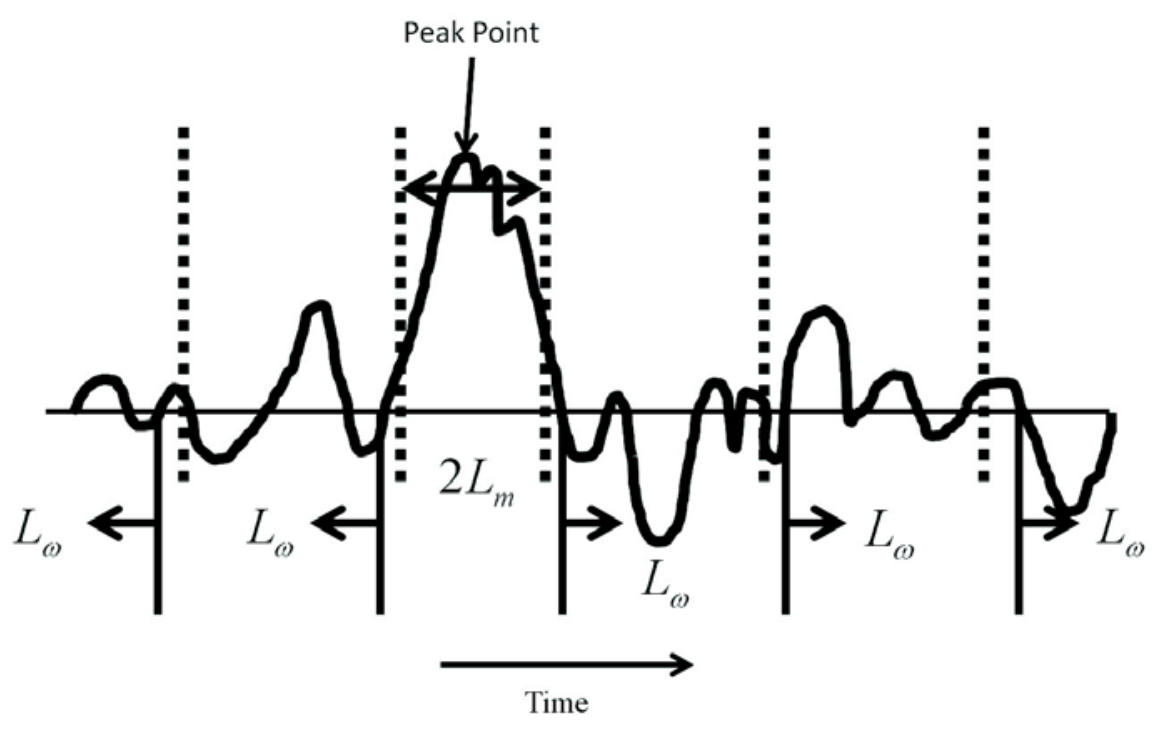

$>$ First step: block separation

Fig.3 An example for a short sentence and blocks

- The main block is selected between the above two zero-crossing points nearby the "Peak Point" .

- The shortest length of other blocks is $L_{\mathrm{w}}$. 


\section{Block Based DRA (2)}

$>$ Second step: determination of the maximum value

- $P_{ \pm \mathrm{i}, \mathrm{j}}$ is defined as the maximum value within the $\pm \mathrm{i}$-th block

- Determine the maximum value among $P_{\mathrm{i}, \mathrm{j}}(\mathrm{i}=1,2, \ldots, \mathrm{M})$ as $T_{1, \mathrm{j}}$.

- If $P_{0, \mathrm{j}}-T_{1, \mathrm{j}}<\sigma_{\mathrm{p}}$ and $T_{1, \mathrm{j}}-P_{\mathrm{i}, \mathrm{j}}<\sigma_{\mathrm{p}}$ then set $P_{\mathrm{i}, \mathrm{j}}$ as the adjustment value.

- If $P_{0, \mathrm{j}}-T_{1, \mathrm{j}}<\sigma_{\mathrm{p}}$ or $T_{1, \mathrm{j}}-P_{\mathrm{i}, \mathrm{j}}<\sigma_{\mathrm{p}}$ then set $P_{\mathrm{i}, \mathrm{j}}=T_{1, \mathrm{j}}$.

- If $P_{0, \mathrm{j}}-T_{1, \mathrm{j}}>\sigma_{\mathrm{p}}$ and $T_{1, \mathrm{j}}-P_{\mathrm{i}, \mathrm{j}}>\sigma_{\mathrm{p}}$ then set $P_{\mathrm{i}, \mathrm{j}}=P_{0, \mathrm{j}}-\sigma_{\mathrm{p}}$.

> Third step: using block based DRA

- In each block, the following block-based DRA is applied:

$$
p_{k, i}^{\prime}=\frac{p_{k, i}}{P_{ \pm i, j}},
$$




\section{Block Based DRA (3)}

$>$ An Example

- The proposed algorithm uses the assumption in which there is not large difference between the adjustment values of neighborhood blocks.

\section{$>$ Parameter Setting $\left(L_{m}\right)$}

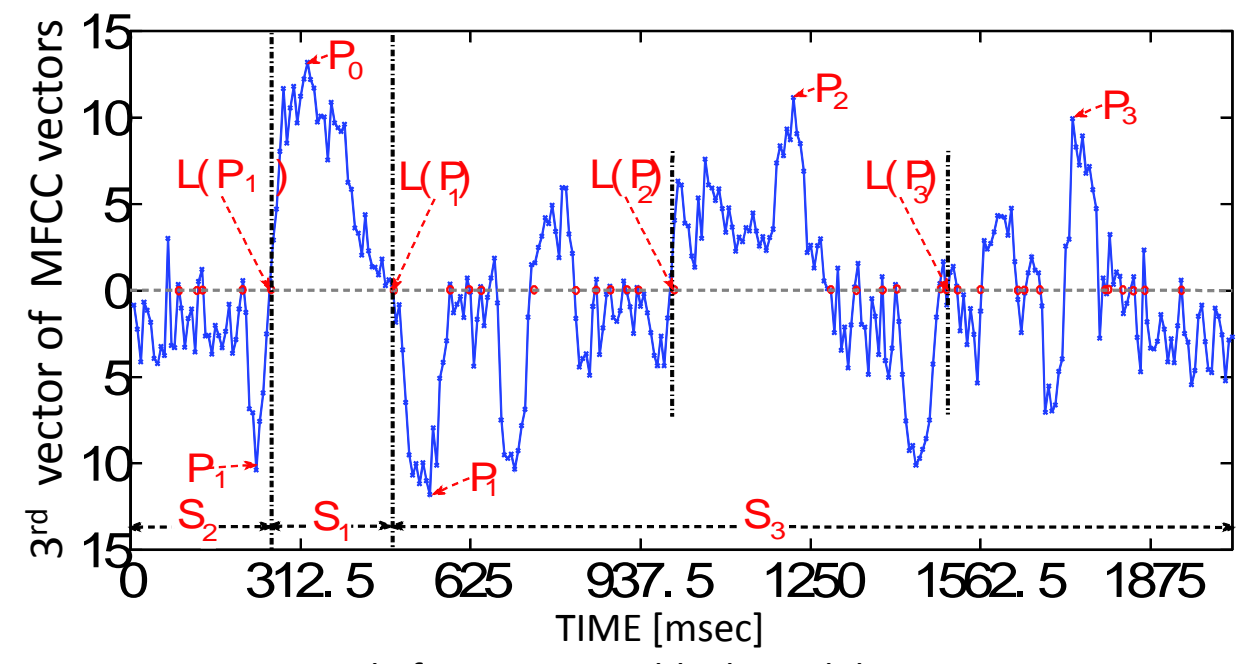

Fig.4 An example for separating blocks and determining maximum

- The main block width includes at least a vowel.

Table 1: Long vowel frame average length

\begin{tabular}{|c|c|c|c|}
\hline Phoneme & Means & Variance & Appear Times \\
\hline a: & 13.35 & 13.50 & 2054 \\
\hline e: & 14.46 & 15.59 & 12688 \\
\hline i: & 14.93 & 20.97 & 1724 \\
\hline o: & 13.83 & 19.01 & 37657 \\
\hline u: & 10.64 & 17.50 & 4831 \\
\hline
\end{tabular}




\section{Block Based DRA (4)}

\section{$>$ Parameter Setting $\left(L_{\mathrm{w}}\right)$}

- The recognition result becomes high when we set $L_{\mathrm{w}}=80$.

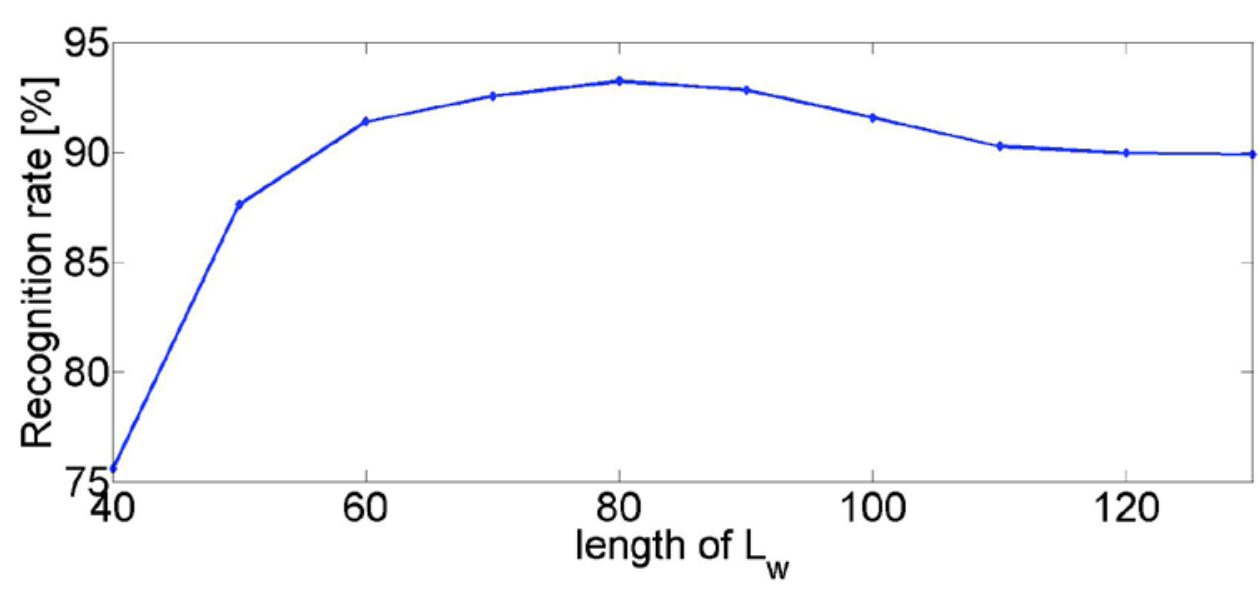

Fig.5 Recognition rate with different $L_{w}$

$>$ Parameter Setting $\left(\sigma_{\mathrm{p}}\right)$

- The adjustment value focuses on preserving the continuity of the continuous speech features and keeping the relationship between the neighborhood blocks.

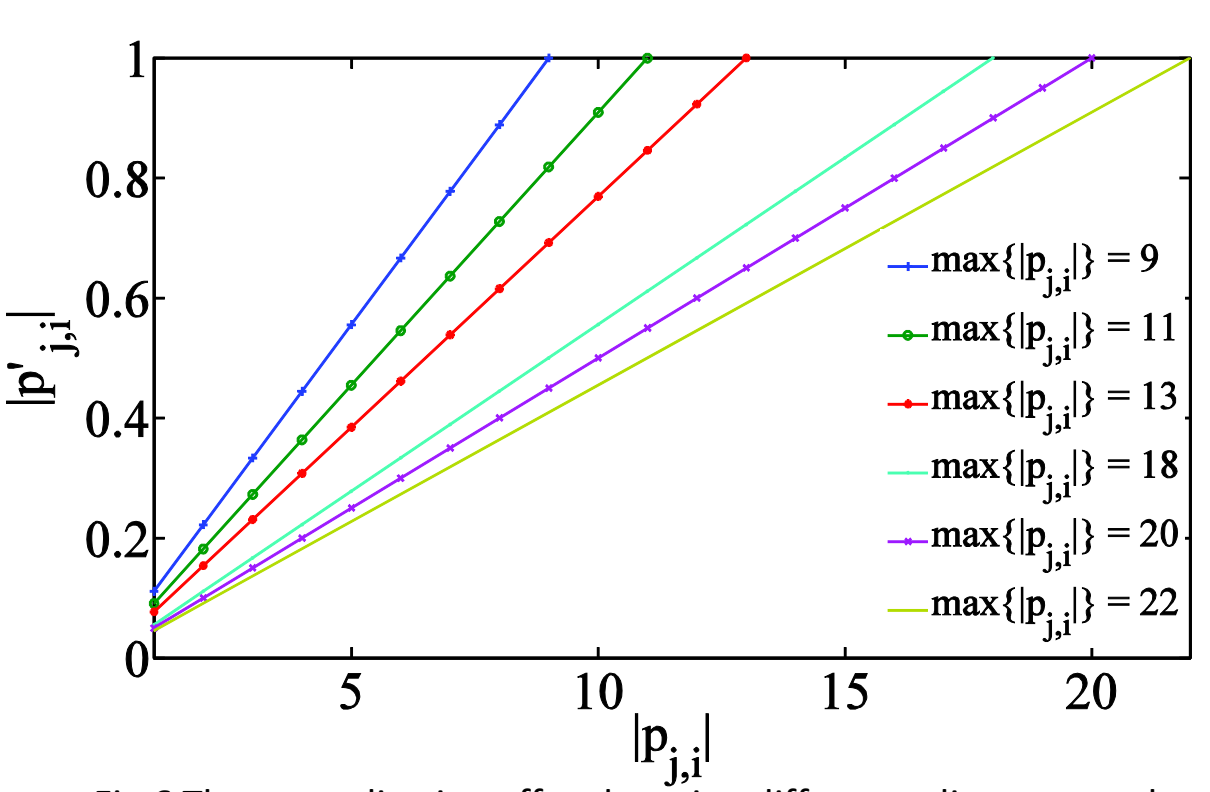

Fig.6 The normalization effect by using different adjustment values 


\section{Block Based DRA (5)}

\section{$>$ Simulation}

- The proposed method effectively increases the similarity between clean and noisy speech features, especially in the marked position from $A$ to $F$.

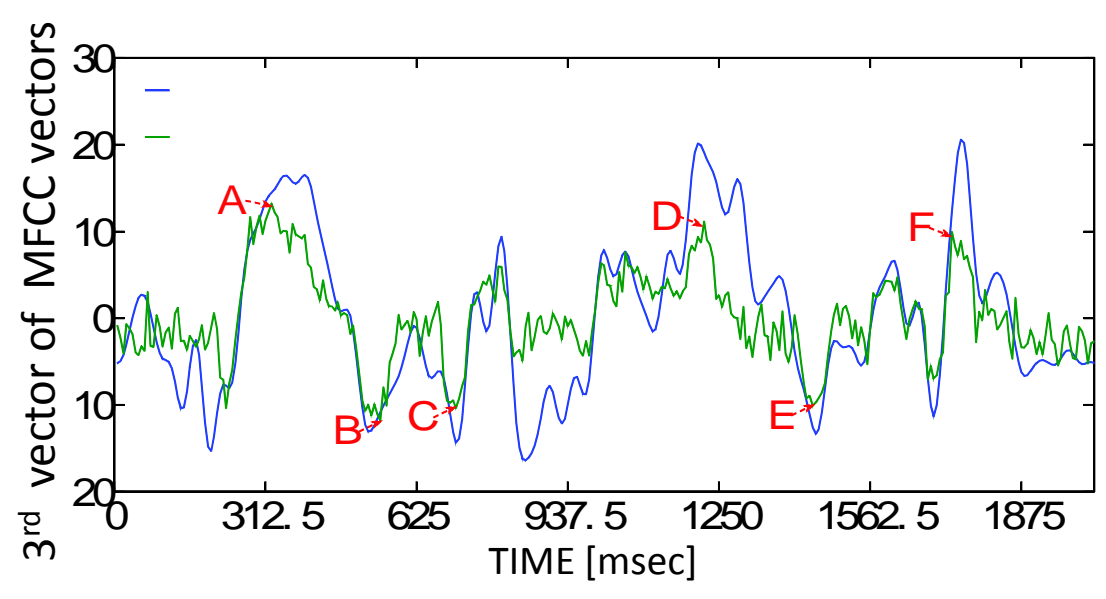

Fig. 7 Before DRA in CSR
Table 2: Acoustic analysis conditions

\begin{tabular}{ll}
\hline Sampling frequency & $16 \mathrm{kHz}$ \\
Frame shift & $10.0 \mathrm{~ms}$ \\
Frame length & $25.0 \mathrm{~ms}$ \\
Window type & Hanning \\
Training data & 23651 sentences from 153 people \\
Emphasizing of High Frequency $1-0.97 z^{-1}$ \\
HMM state number & 5 states \\
& (include start and end states) \\
Number of Gaussian Mixtures & 16 \\
Clustering & about 2000 states \\
\hline
\end{tabular}

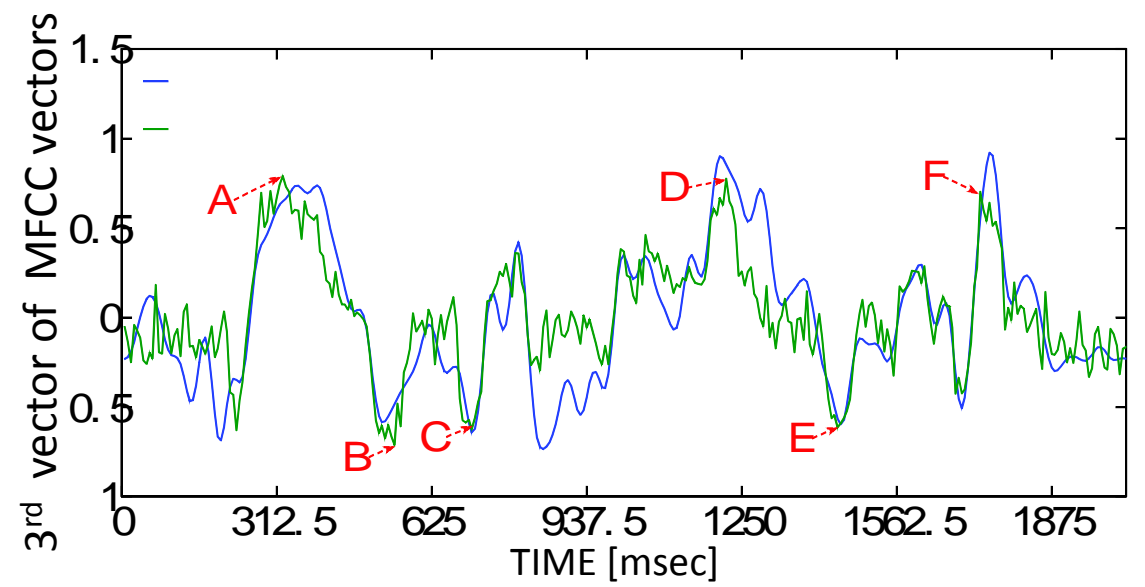

Fig. 8 Results for block based DRA in CSR 


\section{Results}

Table 3: Noise types

\begin{tabular}{|c|c|c|c|c|c|}
\hline \multirow{2}{*}{$\begin{array}{c}\text { Noise } \\
\text { Type }\end{array}$} & babble & buccaneer1 & buccaneer2 & destroyerengniner & destroyerops \\
\cline { 2 - 6 } & $\mathrm{f} 16$ & factory1 & factory2 & hfchannel & leopard \\
\cline { 2 - 6 } (15 kinds) & m109 & machinegun & pink & volvo & white \\
\hline
\end{tabular}

Percent Accuracy $=\frac{N-D-S-I}{N} \times 100 \%$

- Shows accurately the total performance

Percent Correct $=\frac{N-D-S}{N} \times 100 \%$

- Shows the correct word recognition rate

$\mathrm{N}$ : Total number of words

$D$ :Deletion errors

S:Substitution errors

I: Insertion errors
Table 4: Average recognition rates under clean and different SNR conditions

\begin{tabular}{|c|c|c|c|c|c|}
\hline & \multicolumn{2}{|c|}{ Proposed } & \multicolumn{2}{|c|}{ Original } \\
\hline & & Corr. & Acc. & Corr. & Acc. \\
\hline \multicolumn{2}{|c|}{ known (clean) } & 93.22 & 92.29 & 92.69 & 91.49 \\
\hline \multicolumn{2}{|c|}{ unknown (clean) } & 83.90 & 82.43 & 82.77 & 81.52 \\
\hline & $\mathrm{SNR}=20 \mathrm{~dB}$ & 80.08 & 77.72 & 77.80 & 75.82 \\
\hline & $S N R=15 d B$ & 68.06 & 64.81 & 61.10 & 58.40 \\
\hline & $S N R=10 \mathrm{~dB}$ & 49.93 & 46.25 & 39.23 & 36.04 \\
\hline \multirow[b]{3}{*}{$\bar{\Xi}$} & $S N R=20 \mathrm{~dB}$ & 73.76 & 71.31 & 72.46 & 70.23 \\
\hline & $S N R=15 d B$ & 63.01 & 60.14 & 58.18 & 55.95 \\
\hline & $S N R=10 \mathrm{~dB}$ & 47.91 & 44.75 & 37.06 & 35.19 \\
\hline
\end{tabular}


Thank you!

\section{Question?}

